\title{
A Didática Hoje: reinventando caminhos
}

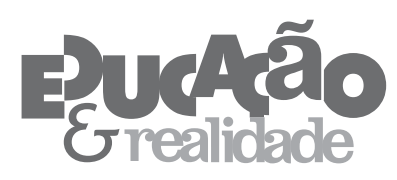

\author{
Vera Maria Ferrão Candau' \\ Adélia Maria Nehme Simão e Koff' \\ 'PontifíciaUniversidadeCatólica do Rio deJaneiro (PUC-Rio), Rio deJaneiro/RJ-Brasil
}

RESUMO - A Didática Hoje: reinventando caminhos. Trata-se de refletir acerca de caminhos possíveis para reinventar a escola e a Didática, tendo presente estudo de caso realizado em uma escola particular do município do Rio de Janeiro e que, optando por desenvolver seu trabalho centrado em projetos e orientado por uma perspectiva intercultural crítica, promoveu uma ampla reorganização de: tempos e espaços, ofício de aluno/a e de professor/a, conhecimentos, currículos, práticas para aprendizagem e avaliação, ritos, estratégias de gestão, entre outras dimensões que entendemos configuram o formato escolar. São reflexões que, longe de esgotar a temática ou serem prescritivas, têm como objetivo oferecer contribuição para os avanços do conhecimento no campo.

Palavras-chave: Educação Intercultural. Reinvenção da Didática. Trabalho Centrado em Projetos.

ABSTRACT - Didactics Nowadays: reinventing ways. This article aims at
reflecting on possible ways to reinvent school and Didactics. This is a case
study at a private school in the city of Rio de Janeiro which option was to de-
velop a project-centered work oriented by a critical intercultural perspec-
tive. It promoted a wide reorganization concerning: time and space, stu-
dent's and teacher's roles, knowledge, curricula, learning and evaluation
practice, rites, management strategies, and other aspects that we under-
stand as part of the school format. These reflections neither aim to exhaust
the theme nor to be prescriptive. The goal is to offer a contribution for ad-
vancements in the field. Keywords: Intercultural Education. Reinventing Didactics. Project-Centered Work.

Educação \& Realidade, Porto Alegre, v. 40, n. 2, p. 329-348, abr./jun. 2015. 329 http://dx.doi.org/10.1590/2175-623646058 


\title{
Introdução
}

A Didática constitui um campo do conhecimento pedagógico que possui um longo recorrido histórico. De Comênio (1592-1670) e sua Didática Magna (1631), a obra considerada referência fundacional da reflexão sistemática sobre as questões didáticas, muitas foram as contribuições, discussões e diferentes correntes e tendências do pensamento filosófico, sociológico e educacional que contribuíram para o seu desenvolvimento.

É possível afirmar que a Didática sempre interagiu com os diferentes momentos históricos, com as diversas visões que seus autores tinham/têm do papel social da educação e da escola.

No que diz respeito a nosso país, a produção da área, especialmente a partir dos últimos trinta anos, tem sido ampla, plural e criativa. Certamente a década de 80 significou um marco muito importante para este campo de conhecimento e criou uma convergência em torno da perspectiva crítica, sem que este fato significasse uma homogeneização de enfoques e preocupações.

Maria Rita Sales Neto de Oliveira, integrante da mesa redonda, no X Encontro Nacional de Didática e Prática de Ensino (ENDIPE), realizado no Rio de Janeiro, em 2000, dedicada à análise dos então praticamente 20 anos de realização dos ENDIPEs, afirma em relação à década dos 80:

\begin{abstract}
Pode-se constatar, então, o fato de que, para além das diferentes posições sobre o objeto de estudo da área, o que existe é um grande consenso. Ele se refere à luta em defesa da legitimidade do saber didático-pedagógico, enquanto constituindo um campo de conhecimento e enquanto conteúdo do currículo da formação do educador, no contexto da luta pela especificidade e importância do papel dos processos da educação e do ensino, no movimento de recuperação e democratização da escola pública e na transformação social (Oliveira, 2000, p. 164-165).
\end{abstract}

Dos anos 90 até hoje, periodicamente, atores fundamentais do campo da Didática realizaram balanços críticos e reflexões sobre o desenvolvimento do mesmo. Alguns deles foram: Pimenta (2000; Pimenta et al., 2013); Libâneo (2000; Libâneo, 2008); Candau (2008); André (2008); Gatti (2008); Marcondes e Leite (2011), entre outros.

Diferentes leituras. Enfoques variados. Ênfases diferenciadas. Certamente estes trabalhos evidenciam a riqueza da pesquisa e reflexão em Didática nos últimos anos.

Partindo do reconhecimento da significativa produção do campo, gostaríamos de assinalar que nos últimos anos emergem buscas para ressignificar o conhecimento sobre Didática, no sentido de construir abordagens e perspectivas que ofereçam elementos para se enfrentar

330 Educação \& Realidade, Porto Alegre, v. 40, n. 2, p. 329-348, abr./jun. 2015. 
os desafios atuais da educação escolar. É o que vimos identificando nas pesquisas que realizamos através do grupo que coordenamos, assim como das discussões que temos presenciado e/ou das quais temos participado em distintos espaços acadêmicos sobre a atual configuração do campo da Didática.

É nesta perspectiva que se situa o presente trabalho que visa contribuir para uma reconfiguração da Didática no momento atual. Pretendemos discutir as possibilidades e dificuldades da articulação entre metodologia de projetos e educação intercultural, tendo por referência uma experiência desenvolvida no ensino fundamental. Está estruturado em dois momentos: a análise de alguns desafios que a educação escolar hoje apresenta para a Didática e uma abordagem que acreditamos oferecer um caminho inspirador para a construção de uma Didática que favoreça a reinvenção da escola e das práticas pedagógicas: o diálogo entre a perspectiva intercultural crítica e a metodologia de projetos.

\section{A Didática e a Educação Escolar Hoje}

Muitas são as discussões atuais sobre o sentido da escolarização, os desafios que enfrentam os sistemas de ensino, a problemática cotidiana da educação escolar, particularmente o Ensino Fundamental e Médio. Basta ler os jornais diários de ampla circulação e/ou assistir os jornais televisivos para constatar a pluralidade de questões que atravessam hoje a dinâmica escolar. A escola está na ordem do dia: universalização da escolarização, qualidade da educação, projetos politico-pedagógicos, dinâmica interna das escolas, concepções curriculares, relações com a comunidade, função social da escola, gestão educacional, sistemas de medição no plano internacional e nacional, formação e condições de trabalho de professores/as, manifestações de violência e bullying na escola, entre outras.

Junto às condições de trabalho precárias que a grande maioria dos/as professores/as vive, é possível detectar um crescente mal-estar entre os profissionais da educação. Insegurança e stress parecem cada vez mais acompanhar o dia a dia dos docentes. Sua autoridade intelectual e preparação profissional são frequentemente questionadas. O impacto das tecnologias da informação e da comunicação sobre os processos de ensino-aprendizagem obriga a buscar novas estratégias pedagógicas. Os sujeitos da educação, crianças e adolescentes, apresentam configurações identitárias e subjetividades fluidas que escapam à compreensão dos educadores/as. Diante deste quadro muitos/as evadem da profissão e procuram caminhos mais tranquilos e seguros de exercício profissional. Tendo presente esta realidade sombria, é possível detectar diferentes modos de abordá-la. Destacaremos dois que nos parecem especialmente presentes na nossa realidade.

O primeiro está configurado por considerar os problemas que afetam as escolas como disfunções que podem ser resolvidas com a 
implementação de estratégias de gestão mais eficientes e sistemas de avaliação, controle e monitoramento. A lógica da produtividade é considerada fundamental e a avaliação de resultados, tanto do desempenho de alunos/as, quanto de professores/as e escolas se impõe. Assistimos nos últimos anos a afirmação desta perspectiva que inspira e estrutura muitas das políticas públicas na área de educação.

No entanto, é possível também situar a crise da educação escolar em um nível mais profundo e radical. A posição de François Dubet (2011) nos parece que é representativa desta posição, com a qual nos identificamos:

Em todos os lugares e não somente na escola, o programa institucional [republicano] declina. E essa mutação é muito mais ampla que a simples confrontação da escola com novos alunos e com os problemas engendrados por novas demandas. É também porque se trata de uma mutação radical, a identidade dos atores da escola fica fortemente perturbada, para além dos problemas específicos com os quais eles se deparam.

A escola foi um programa institucional moderno, mas um programa institucional apesar de tudo. Hoje somos "ainda mais modernos", as contradições desse programa explodem, não apenas sob o efeito de uma ameaça externa, mas de causas endógenas, inscritas no germe da própria modernidade (Dubet, 2011, p. 299).

Para esta segunda posição é o próprio formato escolar, marcado pela lógica da modernidade, que está em questão. Este desafio questiona os conhecimentos e as pesquisas vigentes no âmbito da educação e nos obriga a investir numa compreensão mais aprofundada da realidade das escolas e do trabalho docente hoje. A buscar caminhos de promover processos de ensino-aprendizagem mais significativos e produtores de criatividade e à construção de sujeitos plenos, tanto no âmbito pessoal como social. A construir uma educação escolar capaz de dar resposta aos desafios da contemporaneidade Neste sentido, consideramos importante reinventar o campo da Didática, e consideramos que um dos caminhos nesta direção é o diálogo com a perspectiva intercultural crítica e a metodologia de projetos.

\section{Desenvolvendo o Estudo: breves considerações metodológicas}

Antes de apresentar nossas reflexões acerca do movimento realizado por uma escola particular, situada na Zona Sul do Rio de Janeiro, no sentido de sua reestruturação e reorganização e que consideramos ser uma experiência relevante para nos ajudar a pensar e conceber a reinvenção da escola e do campo da Didática, acreditamos ser necessário fazer alguns apontamentos - mesmo que breves - sobre a metodologia de investigação que utilizamos. 
Para começar podemos dizer que foi um estudo de natureza qualitativa, de inspiração etnográfica, buscando conhecer e compreender com maior profundidade a experiência em pauta, identificada pela própria equipe da escola como uma experiência inovadora e tocada por muitos desafios.

Quando chegamos à escola objeto de nosso estudo, sua equipe estava desenvolvendo sistemáticas reflexões, planejamentos e avaliações, quer dizer, estava mergulhada em um intenso trabalho de natureza político-pedagógica, com o objetivo de conceber, planejar, realizar, avaliar e recriar formas alternativas de lidar com o seu currículo e a sua prática didática em todas as suas dimensões, buscando implementar no Ensino Fundamental - do $6^{\circ}$ ao $9^{\circ}$ ano - um trabalho centrado em projetos.

E foi nessa mesma escola que realizamos uma pesquisa de natureza etnográfica procurando olhar, ouvir e escrever (Oliveira, 1998) tudo o que nela acontecia, principalmente no que se referia às ações do $6^{\circ}$ ano e, assim, construir uma descrição e análise bastante ampla e densa, de modo a construir conhecimentos sobre o que estava acontecendo naquela escola e, ao mesmo tempo, encontrar pistas que nos orientassem no sentido da reinvenção do campo da Didática.

$\mathrm{E}$, para fazer isso, além de termos feito uma intensa e sistemática observação participante das reuniões pedagógicas dos/as professores/as do $6^{\circ}$ ano e das atividades vividas pelos/as alunos/as deste mesmo ano nos diferentes espaços escolares (foram 250 horas de observação), de manter sempre atualizado o nosso diário de campo com muitas anotações, entabular várias conversas informais, realizamos entrevistas individuais com a diretora geral da escola (1), com os/as coordenadores/as (4) e com os/as professores/as (11); realizamos também entrevistas coletivas com os/as alunos/as (22), bem como a análise da documentação pedagógica disponível. Todo o nosso esforço foi no sentido não apenas de realizar uma 'descrição densa' (Ryler apud Geertz, 1978), mas também de promover uma articulação entre esse modo de fazer e a teoria que o estava orientando.

Vale observar que estamos cientes de que nosso trabalho é uma interpretação possível, a nossa interpretação, algo modelado, algo construído, fabricado (Geertz, 1978) sobre o nosso objeto de estudo. Reconhecemos que o que realizamos é, portanto, fruto do nosso 'olhar', do nosso 'ouvir' e do nosso 'escrever'. Em outras palavras, é fruto de nossas buscas de uma interpretação antropológica, de uma 'leitura' possível da experiência em pauta (Geertz, 1978, p. 13), embora tenhamos procurado estar sempre atentas ao 'ponto de vista' dos/as protagonistas e analisá-lo segundo uma perspectiva relacional nos 'termos' dos próprios sujeitos que circulavam na escola.

Vale registrar que o motivo de ter centrado a nossa pesquisa nas turmas do $6^{\circ}$ ano do Ensino Fundamental está relacionado a alguns as- 
pectos que consideramos relevantes: (1) o fato da experiência ter sido implantada progressivamente, começando por essas turmas, o que significa que este era o ano que mais tempo tinha de vivência na experiência em pauta ${ }^{1}$, (2) o fato deste segmento contar, portanto, com uma equipe de professores/as que tinha mais tempo de reflexão em torno do trabalho por e/ou com projetos, (3) mas, ao mesmo tempo, ser o ano onde os/as alunos/as experimentavam trabalhar com projetos pela primeira vez, exigindo um constante repensar da proposta em função dos novos grupos que se formavam, (4) a importância de poder acompanhar de modo longitudinal e abrangente o desenvolvimento do projetos e, desse modo, analisar as suas diferentes dimensões e as configurações que assumiam ao longo de sua realização, bem como as relações que com ele eram estabelecidas por seus/suas protagonistas e (5) a não viabilidade de fazer um amplo e profundo mergulho (o que entendemos ser uma exigência de um estudo de caráter etnográfico) em todos os anos, já que para fazer isso seria preciso ter uma disponibilidade ainda muito maior de tempo (pessoal e mesmo institucional) para realizar todas as observações e entrevistas necessárias.

Vale por em destaque também as principais questões que orientaram o nosso estudo/pesquisa: (1) que significados os projetos implementados pela escola têm para os diferentes sujeitos neles envolvidos? Melhor dizendo, quais os 'sentidos' atribuídos aos projetos pelos diversos sujeitos que dele participam e/ou o constroem, (2) quais os limites e os alcances desses projetos, enquanto uma alternativa didática inovadora para lidar com diferentes saberes, conhecimentos e culturas que circulam na escola, inclusive para viabilizá-la como um lugar de cruzamento desses mesmos saberes, conhecimentos e culturas, segundo esses mesmos sujeitos? (3) Que potencial têm os projetos de trabalho, enquanto possibilidade de vivência de uma educação intercultural crítica?

Muitos foram os nossos achados, todavia, o que apresentamos a seguir é um breve recorte de todo o nosso material. O que apresentamos aqui serve ao nosso propósito, ou seja, refletir sobre as possibilidades de reinventar a escola e o campo da Didática, tendo presente a perspectiva intercultural crítica e a metodologia de projetos.

\section{A Educação Intercultural Crítica e o Trabalho Centrado em Projetos: construindo caminhos para a reinvenção da escola}

Cabe começar esse item reiterando nossa compreensão de que a educação escolar ainda tem um papel relevante na formação das crianças, dos/as adolescentes e dos/as jovens, mas que, no entanto, é necessário buscar novos caminhos e/ou alternativas que possam ser mobilizadas e apropriadas, na perspectiva da reinvenção dessa escola que entendemos precisa ser mais plural, democrática, capaz de responder 
aos desafios de nossa contemporaneidade e de formar cidadãos e cidadãs, sujeitos da construção de um mundo menos dogmático e mais solidário.

Por sua vez, ressaltamos que, para nós, a reinvenção da escola pressupõe, entre outros aspectos, colocar em debate o modo de viver o currículo e/ou a prática educativa, refletindo e discutindo, portanto, o que entendemos são os seus modos de organizar tempos e espaços, relações, papéis de seus diferentes sujeitos e atores, saberes e conhecimentos, métodos, técnicas e recursos, linguagens, planejamento e avaliação. E, embora reconheçamos que não é suficiente promover transformações de caráter teórico-metodológico para mudar a escola, consideramos que esse é um aspecto significativo para construir uma outra escola e, portanto, uma outra educação, desde que tais mudanças sejam contextualizadas histórica e culturalmente e estejam orientadas por princípios claramente formulados e que expressem respostas às questões: que educação queremos construir? Que sujeitos/atores desejamos ajudar a formar? Ou, em outras palavras, que prática escolar desejamos realizar a serviço de quem e do quê?

\section{A Educação Intercultural Crítica: alguns apontamentos}

Desde 1996, vimos desenvolvendo estudos e pesquisas sobre multiculturalismo e interculturalidade e suas relações com os processos educativos. Durante estes anos realizamos um amplo levantamento bibliográfico da produção sobre esta temática, tanto como contexto estadunidense, quanto no europeu e latino-americano, publicado em diferentes livros e artigos. No contexto do presente trabalho, consideramos importante destacar o caráter polissêmico dos termos multiculturalismo e interculturalidade (Fleury, 2003), a centralidade que as questões suscitadas pelos processos imigratórios tem tido nos estudos recentes realizados no contexto europeu e norte-americano, assim como a originalidade, vitalidade e pluralidade da produção latino-americana (Lopez-Hurtado Quiroz, 2007, p. 15). Esta parte da abordagem que situa a interculturalidade no horizonte da própria construção histórica das identidades latino-americanas e dos processos de reconhecimento/negação que afetam os diferentes sujeitos étnicos e socioculturais que as constituem.

No XII Congresso da Association pour la Recherche Interculturelle (ARIC) realizado em Florianópolis em 2009, Catherine Walsh, professora da Universidad Andina Simon Bolívar (sede do Equador) e especialista no tema, em sua palestra de abertura do evento, distinguiu três concepções principais de educação intercultural. A primeira intitulou de relacional e refere-se basicamente ao contacto e intercâmbio entre culturas e sujeitos socioculturais, entre suas distintas práticas, saberes, valores e tradições. Esta concepção tende a reduzir as relações interculturais ao âmbito das relações interpessoais e minimiza os conflitos e as 
relações de poder. No que diz respeito às outras duas posições, tendo como referência Fidel Tubino (2005), filósofo peruano, a referida autora descreveu e discutiu a interculturalidade funcional e a crítica. No que diz respeito à interculturalidade funcional afirma que está orientada a diminuir as áreas de tensão e conflito entre os diversos grupos e movimentos sociais, sem afetar a estrutura e as relações de poder vigentes. No entanto, colocar estas relações em questão é exatamente o foco da perspectiva da interculturalidade crítica. Trata-se de questionar as diferenças e desigualdades construídas ao longo da história entre diferentes grupos socioculturais, étnico-raciais, de gênero, orientação sexual, entre outros. Parte-se da afirmação de que a interculturalidade aponta à construção de sociedades que assumam as diferenças como constitutivas da democracia e sejam capazes de construir relações novas, verdadeiramente igualitárias entre pessoas e grupos de diferentes referentes socioculturais.

Nossa proposta é que a reinvenção da escola esteja orientada pelos princípios de uma Educação Intercultural Crítica e, consequentemente, esses princípios devem impregnar toda a escola/processos, afetando, portanto todas as suas dimensões e ações.

Para nós, isso significa dizer que consideramos fundamental:

Conceber os processos educacionais como historicamente situados, articular a educação com outros processos sociais, trabalhar sistematicamente a relação teoria-prática, favorecer processos de construção de sujeitos autônomos, competentes, solidários capazes de ser sujeitos de direito no plano pessoal e coletivo, capazes de construir histórias e apostar em um mundo e em uma sociedade diferentes, de utilizar metodologias ativas, participativas, personalizadas e multidimensionais, articuladoras das dimensões cognitiva, afetiva, lúdica, cultural, social, econômica e política da educação (Candau, 2003, p. 60).

Mas significa também

Promover uma educação para o reconhecimento do 'outro', para o diálogo entre diferentes grupos sociais e culturais. Uma educação para a negociação cultural, que enfrenta os conflitos provocados pela assimetria de poder entre os diferentes grupos socioculturais em nossa sociedade, e é capaz de favorecer a construção de um projeto comum, pelo qual as diferenças são dialeticamente integradas (Candau, 2009, p. 59).

Nossa aposta implica, portanto, conceber e realizar processos de ensino-aprendizagem orientados no sentido de: valorizar a construção da autonomia do/a aluno/a, reconhecendo-o/a sujeito da construção de sua história particular e da história em geral; ampliar e/ou reforçar os mecanismos para o seu autoconhecimento, valorizando processos de construção de identidade(s); reconhecer e valorizar os diferentes sujei- 
tos socioculturais presentes na escola e, consequentemente, fazer dialogar os diferentes grupos culturais que nela circulam; empoderar esses diferentes sujeitos e os grupos culturais a que pertencem valorizando sua autoestima; trabalhar os conflitos que emergem das e/ou nas relações interpessoais, apostando no potencial dos mecanismos de negociação e na construção coletiva de normas/regras e/ou códigos de convivência; reconhecer, valorizar, fazer dialogar e/ou articular diferentes saberes, incorporando diversas narrativas e linguagens; valorizar e empregar procedimentos metodológicos diversificados, dando ênfase ao diálogo, à participação e à produção coletiva e/ou colaborativa, sem deixar de valorizar a experiência e a produção de cada um/uma. E, ainda, conceber e realizar processos de ensino-aprendizagem contextualizados, tendo presente que os contextos são multiculturais. Processos de ensino-aprendizagem que, portanto, afirmam, incorporam e se enriquecem com as diferenças culturais, sem negar a busca pela igualdade de direitos. E que também buscam promover o diálogo entre as práticas vividas na escola e as demais práticas sociais (Koff, 2011).

Para nós, apostar na ideia da reinvenção da escola orientada pelos princípios de uma Educação Intercultural Crítica significa reconhecer que a escola tem papel relevante na perspectiva da afirmação da justiça - social, cognitiva e cultural -, assim como da construção de relações igualitárias entre os diferentes grupos socioculturais e da democratização da sociedade, por meio de políticas que articulam os diretos da igualdade e da diferença.

\section{O Trabalho Centrado em Projetos: para além de um recurso metodológico}

Pretendemos, neste item, fazer breves considerações que tratam de alguns aspectos do trabalho centrado em projetos, como um caminho possível para conceber e fazer acontecer a escola na direção aqui sugerida. Mas antes mesmo de avançar nossas reflexões, precisamos fazer dois registros.

O primeiro registro diz respeito ao fato de que entendemos a atual proposta de trabalhar por e com projetos como uma releitura do método de projetos, concebido pelo educador norte americano William Kilpatrick (1918). Fundamentada nos estudos de John Dewey acerca de uma 'escola ativa', sua proposta tem como preocupação central os interesses do/a aluno/a, na perspectiva despertar nele/a a vontade de saber. Kilpatrick e seu método tornaram-se conhecidos no Brasil, a partir do Movimento da Escola Nova, que, em confronto com os princípios e métodos da pedagogia tradicional, propôs a adoção de métodos mais ativos, buscando, principalmente, superar uma perspectiva centrada na transmissão de conhecimentos pelos/as professores/as para incentivar a participação e/ou a atividade intensa dos/as alunos/as na construção do conhecimento.

Educação \& Realidade, Porto Alegre, v. 40, n. 2, p. 329-348, abr./jun. 2015. 
Vale sublinhar, todavia, que entendemos que trabalhar por e com projetos tal como está proposto pelos autores mais contemporâneos (por exemplo, Hernández; Ventura, 1998; Hernandez et al., 2000; Alvarez et al., 2004) tem como princípio superar a dimensão técnica tão presente quando se trata de um 'método', sugerindo uma nova postura, no sentido de se repensar a escola, o seu currículo, a sua prática pedagógica e, consequentemente, o processo de ensino-aprendizagem.

O segundo registro é que não temos a intenção de entender o trabalho centrado em projetos como única alternativa ou que há uma só maneira de conceber e fazer acontecer os projetos. Nossas considerações estão pautadas na observação, análise e interpretação da experiência que foi objeto do nosso estudo. E, nesse caso, reconhecemos que a opção de trabalhar por e/ou com projetos, abrangendo a reorganização da escola como um todo e apoiada pelos princípios da perspectiva intercultural crítica concebidos e construídos de forma compartilhada por todos os envolvidos - direção, equipe técnica, professores/as, alunos/as e suas famílias - pode contribuir para fazer a escola avançar no sentido de, cada vez mais, responder aos seus desafios.

Organizar o currículo, a prática didática e o conhecimento escolar, bem como os tempos, os espaços, os ritos, as estratégias de gestão e outros aspectos que envolvem a dinâmica do funcionamento da escola, tendo por orientação o trabalho centrado em projetos, parece ser muito mais do que adotar uma metodologia diferente ou específica. Trabalhar por e/ou com projetos na escola implica principalmente em adotar outra concepção do que sejam os processos de ensinar e de aprender. E, nesse caso, um aspecto relevante é a ideia de que o/a aluno/a aprende fazendo conexões entre os saberes e os conhecimentos que ele/a já tem e aqueles que ainda precisa construir. Quer dizer: ele/a não aprende por acumulação e/ou por meio da simples transmissão de informações, mas sim e, principalmente, fazendo relações entre diferentes informações, saberes e conhecimentos disponíveis em diversas fontes (ele/a mesmo pode ser uma dessas fontes) e, a partir daí então, tem possibilidade de construir novos conhecimentos. Trata-se de um enfoque globalizador e relacional.

E, embora tal enfoque possa inspirar diferentes "formatos" e, consequentemente, diferentes maneiras de organizar os conhecimentos escolares, segundo Hernández e Ventura (1998, p. 61), o trabalho centrado em projetos possibilita e, até mesmo favorece que a abordagem globalizadora e relacional seja adotada, na medida em que os projetos de trabalho implicam considerar que tais conhecimentos não se ordenam de uma forma rígida, nem em função de algumas referências disciplinares pré-estabelecidas ou de uma homogeneização dos alunos.

No que tange à proposta que analisamos, foi possível registrar um esforço significativo no sentido de dar um tratamento mais globalizado, ou seja, menos fragmentado e mais articulado, integrado e inter- 
disciplinar dos saberes e conhecimentos (com frequência os/as professores/as sublinhavam: é necessário fazer sempre links entre tudo o que estamos trabalhando), permitindo que o/a aluno/a fizesse diferentes conexões entre o que estava estudando/pesquisando e também entre seus estudos e pesquisas e o que ele/a sabia e/ou conhecia. Hernández e Ventura (1998), destacam que os projetos de trabalho favorecem aprendizagens mais significativas, na medida em que estimulam essas conexões. E, afirmam que, quanto mais possibilidades e/ou oportunidades o/a aluno/a tiver para fazê-las, mais favorável será a sua atitude em relação aos saberes/conhecimentos, à sua disponibilidade e interesse para aprender e, nesse sentido, maiores serão as suas possibilidades de realizar aprendizagens significativas.

Para Hernández e Ventura (1998, p. 63), “[...] globalização e significatividade são dois aspectos essenciais que se plasmam nos projetos". Eles destacam que "[...] as informações necessárias para construir os projetos não estão determinadas de antemão, nem dependem do educador ou do livro-texto, estão sim em função do que cada aluno já sabe e da informação com a qual se possa relacionar dentro e fora da escola" (Hernández; Ventura, 1998, p. 64). Ou seja, para Hernández e Ventura (1998), o trabalho centrado em projetos implica o protagonismo dos/as alunos/as desde a seleção dos temas e/ou dos assuntos e/ou das questões que serão objetos de seus estudos, incentivando o diálogo com o que eles/as já trazem de suas próprias vivências. Entendemos que, assim concebidos, os projetos de trabalho, favorecem a circulação e/ou construção de saberes, conhecimentos e culturas, sem hierarquizá-los, respondendo, desse modo, a um dos princípios que consideramos fundamental para a vivência de uma perspectiva intercultural crítica. No entanto, esta não é uma questão fácil, tanto a definição dos temas dos projetos, quanto a dinâmica do seu desenvolvimento. Assistimos intensas discussões entre os educadores em que era possível identificar posições que se orientavam por uma perspectiva crítica e intercultural, procurando situar os temas num contexto social amplo, favorecendo a identificação dos diversos atores nele presentes, assim como valorizando os diversos e plurais saberes. Outros adotavam uma perspectiva mais centrada nos conteúdos curriculares estabelecidos, tendo dificuldades em desnaturalizar estes saberes e incorporar também outros, socialmente produzidos. Esta foi uma tensão recorrente em inúmeros momentos.

Segundo Fernando Hernandez (1998), há algumas etapas que, de um modo geral, caracterizam o trabalho centrado em projetos. $\mathrm{O}$ primeiro passo é o da definição do eixo: tema, problema, conceito ou questão ou, ainda, conjunto de questões inter-relacionadas que se quer investigar, lembrando que o importante é que o eixo seja definido pelos/as alunos/as, de acordo com os seus interesses, prioridades e/ou curiosidades, podendo contar, entretanto, com a parceria dos/as professores/as. Em seguida, é necessário definir múltiplas fontes e diferentes 
procedimentos para buscar essas informações, bem como estabelecer os critérios que vão ajudar a categorizar e interpretá-las. No meio do caminho podem surgir novas perguntas e novos traçados ou desvios são feitos. Novas relações são então estabelecidas. Na verdade, uma rede de achados vai sendo tecida e sistematizada pelos/as alunos/as, procurando sempre dialogar com suas experiências e saberes. No final, eles/as devem expressar suas descobertas de diferentes maneiras, concebendo, elaborando e/ou criando diferentes produtos - relatórios, dossiês, textos em prosa ou verso, desenhos, programas para Rádio, TV ou WEB, painéis, exposições, dramatizações -, utilizando, portanto, diferentes linguagens e construindo diferentes narrativas.

No caso da escola, objeto de nosso estudo, por exemplo, constatamos que os/as alunos/as apresentavam suas demandas temáticas (quase sempre uma extensa listagem) que eram então categorizadas e organizadas em um mapa conceitual, detalhadas em um índice de assuntos correlacionados e traduzidas em desafios/metas a serem alcançadas, sempre com a colaboração dos/as professores/as. Tal colaboração era justificada, na medida em que as crianças (lembramos que nosso estudo estava centrado no sexto ano, portanto com alunos/as entre $10 \mathrm{e}$ 11 anos), estavam em processo de aprendizagem da própria sistemática do trabalho centrado em projetos. Percorrendo, passo a passo, os caminhos traçados para dar conta dos seus desafios e/ou de suas metas, os/as alunos/as iam realizando aprendizagens e construindo conhecimentos.

Entendemos, portanto que a experiência que analisamos pode ser compreendida como uma experiência que abre caminho para reposicionar o conhecimento escolar e a própria função da escola, na medida em que procurava favorecer a busca das informações disponíveis em vários meios e/ou linguagens, bem como a sua transformação em conhecimentos, na perspectiva de ajudar os/as alunos/as a uma melhor inserção crítica no mundo em que vivem. Uma proposta que valoriza a ideia de que é o/a aluno/a quem constrói conhecimentos, a partir das relações que ele/a estabelece com o 'outro' e com diferentes tipos de experiências e que, portanto, pressupõe uma outra concepção de sociedade, como expressaram vários/as professores/as. E, nesse sentido, pode ser compreendida como uma proposta que, além de ser

Um guia aberto à intervenção educativa, inclui as aprendizagens que os alunos efetuam à margem das intenções do corpo docente, quer seja pelas relações de comunicação estabelecidas com seus pares, com os professores e os adultos, quer seja pelo acesso a uma maior variedade de recursos (livros, filmes, laboratórios, oficinas, visitas, excursões, etc.) que lhes proporcionam possibilidades que não podemos prever totalmente (Torres Santomé, 1998, p. 28-29).

A afirmação do protagonismo dos/as alunos/as e o trabalho coletivo é um componente fundamental do trabalho com projetos mas para 
que possa situar-se na perspectiva da interculturalidade crítica, é importante favorecer continuamente as relações e trabalho conjunto entre sujeitos diferentes e procurar que os temas desenvolvidos sejam contextualizados, tendo-se presente as relações sociais e seus conflitos.

Constatamos também que o trabalho por e/ou com projetos potencializava dinâmicas voltadas para o aprender a aprender, valorizando o/a aluno/a enquanto sujeito/ator, ou seja, enquanto protagonista desse processo, favorecendo aprendizagens mais significativas para ele/a. O tempo todo o/a aluno/a era estimulado a pensar e decidir sobre o percurso que ia realizar para fazer suas aprendizagens. Ele/a fazia isso individualmente ou de forma coletiva, ou seja, contando com o apoio de outros/as alunos/as ou com a ajuda dos/as professores/as. Entendemos, portanto que trabalhar por e/ou com projetos implica reinventar o ofício de aluno/a e o do/a professor/a, rompendo com a fórmula mais clássica: professor/a ensina e aluno/a aprende ou não.

No entanto, isto nem sempre acontecia. Como já afirmamos, várias tensões se faziam presentes entre os professores/as, no que diz respeito a favorecer o diálogo com os diferentes, o trabalho coletivo e a contextualização. Alguns professores/as já tinham estas preocupações internalizadas mas outros tendiam a estruturar demasiado as atividades, deixar fluir processos autorreferenciados e fundamentalmente individuais, assim como resistiam a desconstruir o papel tradicional do/a professor/a como possuidor de um conhecimento que deve ser transmitido aos alunos/as.

Por sua vez, na escola objeto de nosso estudo, foi possível constatar que o trabalho centrado em projetos favorecia o empoderamento do/a aluno/a, uma vez que como protagonista de muitas estratégias e/ou atividades que eram desenvolvidas, ele/a ia conquistando sua autonomia para aprender e para agir em diferentes situações, desenvolvendo sua competência como pesquisador/a crítico/a e sua criatividade. Favorecia também, em consonância com a perspectiva intercultural crítica, a valorização da sua identidade cultural, na medida em que ele/a, em função das diversas oportunidades que lhe eram dadas, podia se expressar, partilhar seus saberes e produzir conhecimentos, a partir, inclusive, de seu pertencimento cultural. Além disso, identificamos que os projetos estimulavam os/as alunos/as a aprenderem a trabalhar de modo mais solidário e colaborativo, já que as estratégias de trabalho em pequenos grupos eram frequentemente mobilizadas.

Outro aspecto importante que merece registro é que, na escola que analisamos, para dar vida aos projetos, eram utilizadas estratégias, atividades, procedimentos didáticos e recursos muito diversificados, incluindo os tecnológicos e bastante lúdicos (várias vezes sugeridos e/ou construídos pelos/as próprios/as alunos/as), garantindo, desse modo, uma dinâmica que parecia dar conta da agitação própria das crianças e dos/as adolescentes - eles pareciam se divertir enquanto aprendiam, 
além de criar oportunidade de aprendizagens, respeitando e contemplando a pluralidade de características socioculturais dessas crianças e adolescentes, o que parecia mobilizá-los/as e mantê-los/as bastante interessados/as em aprender.

Por sua vez, com frequência e em função dos objetivos do projeto que estavam realizando, os/as alunos/as eram estimulados/as a desenvolver atividades, contando com a participação de convidados que eram chamados para partilhar suas experiências vividas em outras instâncias e/ou grupos culturais. Já em outras ocasiões, eram levados para realizar atividades em outros lugares para além dos muros da escola. Estratégias que entendemos favoreciam uma maior aproximação entre a escola e outras instâncias ou espaços de aprendizagem e, consequentemente, a vivência de uma pluralidade de experiências, criando, inclusive, oportunidades de diálogo com diferentes grupos culturais, Consideramos este um aspecto de especial importância para a perspectiva da educação intercultural: ampliar o horizonte da escola, favorecer a interação com distintos grupos socioculturais, reconhecer os diversos atores sociais e as relações e conflitos existentes entre eles.

Cabe aqui esclarecer que a escola organizava seu trabalho dividindo o seu tempo em dois momentos articulados: o primeiro - com cerca de $2 \mathrm{~h}$ - denominado de trabalho pessoal, bastante flexível onde um/a professor/a (independente de sua área e/ou formação específica), tendo presente o tema e as questões formuladas, estimulava e orientava o/a aluno/a na realização de suas pesquisas, na organização e processamento das informações coletadas e na elaboração de suas sínteses. Já o segundo momento - chamado de estudo específico das disciplinas - era dedicado ao aprofundamento dos achados obtidos no momento anterior, sendo que agora os/as professores/as contribuíam com os conhecimentos específicos de sua área de formação. Observamos que todo o esforço feito era no sentido de articular e integrar esses diferentes momentos, buscando fazer links entre os saberes e conhecimentos neles trabalhados e flexibilizar as fronteiras disciplinares.

Tal organização temporal expressava a dificuldade de romper definitivamente com a organização curricular disciplinar e as tensões existentes entre o professorado em relação a este tema, mas já apontava uma possibilidade bastante produtiva desse rompimento, na medida em que os temas trabalhados nos projetos tinham o propósito não só de gerar os estudos, as pesquisas, bem como a construção de saberes e de conhecimentos, mas principalmente permitir que esses saberes e conhecimentos fossem tratados em uma perspectiva mais integrada e globalizadora, fazendo, portanto, mais sentido para os/as alunos/as.

Também merece destaque o papel dos diferentes espaços escolares utilizados no trabalho por e/ou com projetos na escola aonde realizamos a nossa pesquisa. Um papel, que, segundo entendemos, contribuía para favorecer aprendizagens significativas, respeitando, valorizando e fazendo dialogar as diferentes identidades culturais dos/as alunos/as, 
na medida em que eram espaços que acolhiam e estimulavam a produção das crianças e dos/as adolescentes nos seus próprios termos. Suas linguagens e/ou narrativas encontravam, nos diferentes espaços que eram utilizados para dar vida aos projetos de trabalho, inúmeras possibilidades de expressão.

Durante a realização das atividades, diversos e diferentes ambientes que integravam a arquitetura escolar eram utilizados como $l u$ gar de aprendizagem, sugerindo a valorização de um conceito de sala de aula, que vai muito além dos espaços convencionais a ela destinados, seja pela presença de vários lugares que podiam ser usados pelos alunos para brincar, jogar e praticar esportes, mas também para estudar, fazer pesquisas, realizar experimentos, produzir e criar, seja pela adoção de um mobiliário que favorecia a prática de atividades coletivas (as mesas e as cadeiras, por exemplo, foram desenhadas para favorecer o trabalho em pequenos grupos), seja pela possibilidade até mesmo de usar o chão do corredor como uma imensa mesa para realização de trabalhos coletivos, seja pela presença de múltiplos equipamentos e/ou recursos didáticos (do livro aos recursos de computação e multimídia) que estimulavam e davam suporte à realização das várias atividades previstas pelo projeto, tais como: pesquisas em livros e computadores, experimentos em laboratórios, produção de audiovisuais, realização de exposições, exibição de peças de teatro, exibição e debate em torno de filmes exibidos na própria escola. A ruptura com o ensino frontal e a promoção da diferenciação pedagógica constituem elementos significativos para a promoção de uma educação intercultural. Aqui também nem sempre era fácil promover este ambiente, alguns professores/as consideravam que faltava ordem, disciplina, não valorizando a dinâmica que se promovia.

Cumpre ressaltar que constatamos também a presença, nos diferentes ambientes, de muitos painéis relacionados aos temas e/ou aos assuntos das pesquisas, estudos e atividades em andamento, além de vários cartazes associados a campanhas de mobilização e/ou conscientização quase sempre voltados para questões e/ou situações que estavam na ordem do dia.

Acreditamos que é possível dizer que esses painéis e cartazes, ao lado da configuração e apropriação dos espaços arquitetônicos e/ou ambientes escolares e seus equipamentos e/ou recursos compunham um cenário bastante plural, diversificado e em constante movimento que pode ser compreendido como um programa educador que incorpora e/ou responde aos padrões culturais e pedagógicos presentes na escola (Escolano, 2001) e que, nesse sentido, contribuía para reforçar aspectos valorizados pelo trabalho centrado em projetos e na perspectiva intercultural crítica como, por exemplo: o trabalho coletivo que estimulava o diálogo com o outro, a produção dos/as próprios/as alunos/as, utilizando diferentes linguagens e narrativas, a circulação de diferentes saberes e conhecimentos, promovida pela vivência de uma gama plural 
de atividades e o diálogo com questões que fazem parte do cotidiano e/ou da realidade que ultrapassa os muros escolares, dialoga com outras práticas socioculturais, na direção de uma formação comprometida com a transformação da sociedade.

Tendo presente toda essa reconfiguração do formato escolar gerada pela opção de se trabalhar por e/ou com projetos iluminada pela perspectiva intercultural crítica, não poderíamos deixar de apontar um aspecto fundamental que observamos na dinâmica da escola aqui retratada e que muitas vezes é responsável pelo engessamento e/ou pela colocação de limites quando desejamos propor uma reinvenção da escola e da Didática em uma perspectiva intercultural crítica. Estamos nos referindo à avaliação da aprendizagem, que também mereceu atenção e sobre a qual incidiram transformações geradas pela opção de trabalhar por e/ou com projetos.

Nesse caso, consideramos importante sublinhar que eram utilizadas diferentes estratégias e/ou procedimentos de avaliação da aprendizagem, abrangendo tanto o momento do trabalho pessoal, como o dos estudos específicos das disciplinas e que podem ser assim sistematizados: o processo e/ou sistema de avaliação da aprendizagem era bimestral, incluindo (1) autoavaliação individual e, às vezes, coletivas, registrada em fichas específicas pelo/a próprio/a aluno/a, (2) avaliação feita pelo/a professor/a do processo vivido pelos/as estudantes, levando em conta o resultado do desempenho em cerca de quatro ou cinco atividades realizadas no momento do trabalho pessoal, incluindo a qualidade do texto do relatório-síntese, além de aspectos relacionados à organização, cooperação, participação e respeito às diferenças, (3) avaliação feita pelo/a docente do produto, considerando outros exercícios e provas realizados pelos/as alunos/as.

Um processo e/ou sistema que parecia, portanto, ser abrangente e diversificado, buscando superar um conceito mais restrito de avaliação, ou seja, mais centrada em produto ou apenas em provas (embora elas 'valessem mais pontos'), para favorecer uma avaliação da aprendizagem mais compatível com os princípios e práticas que eram valorizados no desenvolvimento dos projetos de trabalho. Portanto, um processo e/ou sistema de avaliação da aprendizagem que parecia procurar fugir de uma avaliação meramente classificatória e/ou seletiva, para ser um processo que também valorizava uma avaliação mais formativa, mesmo considerando que os resultados das provas tivessem maior peso. Em outras palavras, embora os aspectos relacionados à aprendizagem de conteúdos/conhecimentos fossem priorizados, constatamos que questões como a aprendizagem de habilidades, bem como o desenvolvimento de valores, de atitudes frente aos/às colegas, aos/às professores/as e ao trabalho, a prática da autoavaliação, os mecanismos adotados para aprender a aprender também eram objeto de observação e análise para compor o quadro da avaliação dos/as alunos/as. 
Mesmo assim, observamos que essa era uma prática que suscitava resistências o que dificultava poder avançar ainda mais, buscando, por exemplo: (1) diminuir o peso das provas mais vinculadas ao momento do estudo específico das disciplinas e, paralelamente, aperfeiçoar a avaliação das aprendizagens - acerca de conceitos e conhecimentos - feitas durante o momento do trabalho pessoal; (2) promover constante realimentação ou reorientação dos/as alunos/as, a partir dos resultados que eles/as tinham alcançado, de modo que durante o processo de aprendizagem eles/as pudessem rever, corrigir e alterar tais resultados; (3) favorecer processos de avaliação inter-pares e coletiva; (4) procurar criar menos hierarquias entre as avaliações do domínio cognitivo e aquelas voltadas à construção de habilidades e atitudes; (5) criar mecanismos para ampliar a percepção quanto à qualidade dos textos-sínteses elaborados pelos/as alunos/as; (6) fazer do momento de socialização dos dados e/ou das informações pesquisadas um momento efetivo de troca e aprendizagem; (7) aperfeiçoar os critérios de análise das atividades realizadas pelas/os crianças/adolescentes.

Mesmo apresentando limites e resistências, é possível dizer que o processo e/ou sistema de avaliação da aprendizagem concebido e vivido naquela escola parecia estar criando mais oportunidades, no sentido dos/as estudantes assumirem maior responsabilidade sobre suas aprendizagens (Hargreaves, 2002) e dos/as professores/as ampliarem o diálogo com as/os crianças/adolescentes, construindo e reconstruindo com eles/as esse processo de aprendizagem. O que, entendemos, é coerente com a orientação de que no trabalho centrado em projetos, articulado com a perspectiva da interculturalidade crítica, os/as alunos/as - individual e grupalmente - devem ser protagonistas na maior parte do processo, inclusive durante os momentos de avaliação.

\section{A Título de Conclusão}

Tendo presente os resultados de o estudo de caso que realizamos, é possível afirmar que o trabalho com projetos, articulado à perspectiva intercultural crítica é possível e favorece processos de reinvenção da escola colocando em questão o formato escolar dominante. No entanto, não se trata de um processo fácil. Se o trabalho centrado em projetos articulado com a perspectiva da educação intercultural rompe com as formas mais usuais de organizar os espaços e os tempos escolares, as informações, os saberes e os conhecimentos, bem como as relações entre os diferentes sujeitos, as práticas escolares e as leituras da realidade em que estamos imersos, suscita também resistências e conflitos. Principalmente porque desconstrói o formato escolar vigente e as concepções de professor/a, aluno/a, conhecimento vigentes, fortemente arraigadas nos professores e professoras e, nos atreveríamos a afirmar, na sociedade e mesmo reforçadas pelas políticas públicas.

Educação \& Realidade, Porto Alegre, v. 40, n. 2, p. 329-348, abr./jun. 2015. 
A educação intercultural crítica vem se afirmando entre nós. No entanto, tem apresentado grandes desafios na sua incorporação à dinâmica escolar. Acreditamos que a articulação com a metodologia de projetos oferece um caminho promissor para o seu desenvolvimento.

Reinventar a escola, reinventando seu modo de ser e agir, tendo como alternativa o trabalho centrado em projetos, configurados segundo os princípios da perspectiva intercultural crítica, parece ser não só uma possibilidade - mesmo que sua implementação exija superar conflitos, romper com rotinas já cristalizadas, se envolver com ações cooperativas, realizar muitas pesquisas, estar disposto a aprender de forma solidária e pleno compromisso e engajamento profissional -, como também um caminho viável e promissor para a reinvenção da Didática como campo teórico-prático do conhecimento pedagógico.

Recebido em 30 de março de 2014 Aprovado em 04 de janeiro de 2015

\section{Nota}

1 É importante lembrar aqui que a escola começou a conceber, planejar e discutir a reorganização de seu formato escolar, na perspectiva desenvolver trabalhos centrados em projetos, em 2002, sendo eles desenvolvidos já desde o primeiro semestre de 2003.

\section{Referências}

ÁLVAREZ, Manuel et al. O Projeto Educativo da Escola. Porto Alegre: ARTMED Editora, 2004.

ANDRÉ, Marli. Tendências da Pesquisa e do Conhecimento Didático no Início dos Anos 2000. In: ENCONTRO NACIONAL DE DIDÁTICA E PRÁTICAS DE ENSINO, 14., 2008, Porto Alegre. Anais... Porto Alegre: PUC-RS, 2008. P. 487-499.

CANDAU, Vera Maria. Pedagogias Críticas: ontem e hoje. Revista Novamerica, Rio de Janeiro, n. 97, p. 58-61, mar. 2003.

CANDAU, Vera Maria. Memórias, Diálogos e Buscas: aprendendo e ensinando didática. Revista Educação, São Leopoldo, v. 12, p. 174-181, 2008.

CANDAU, Vera Maria. Educação Escolar e Culturas: multiculturalismo, universalismo e currículo. In: CANDAU, Vera Maria (Org.). Didática: questões contemporâneas. Rio de Janeiro: Forma \& Ação, 2009. P. 47-60.

COMÊNIO, João Amos. Didática Magna. 4. ed. São Paulo: Martins Fontes, 2011.

DUBET, François. Mutações Cruzadas: a cidadania e a escola. Revista Brasileira de Educação, Rio de Janeiro, v. 16, n. 47, p. 289-322, maio/ago. 2011.

ESCOLANO, Agustín. Arquitetura como Programa. Espaço-escola e currículo. In: FRAGO, Antonio Viñao; ESCOLANO, Agustín. Currículo, Espaço e Subjetividade: a arquitetura como programa. 2. ed. Rio de Janeiro: DP\&A, 2001. P. 19-57. FLEURY, Reinaldo Matias. Intercultura e Educação. Revista Brasileira de Educação, Rio de Janeiro, n. 23, p. 16-35, maio/ago. 2003

346 Educação \& Realidade, Porto Alegre, v. 40, n. 2, p. 329-348, abr./jun. 2015. 
GATTI, Bernadete. A Pesquisa e a Didática. In: ENCONTRO NACIONAL DE DIDÁTICA E PRÁTICAS DE ENSINO, 14., 2008, Porto Alegre. Anais... Porto Alegre: PUC-RS, 2008. P. 67-76.

GEERTZ, Clifford. Uma Descrição Densa: por uma teoria interpretativa da cultura. In: GEERTZ, Clifford. A Interpretação das Culturas. Rio de Janeiro: Zahar, 1978. P. 3-21.

HARGREAVES, Andy et al. Aprendendo a Mudar: o ensino para além dos conteúdos e da padronização. Porto Alegre: Artmed, 2002.

HERNÁNDEZ, Fernando. Transgressão e Mudança na Educação: os projetos de trabalho. Porto Alegre: Artmed, 1998.

HERNÁNDEZ, Fernando et al. Aprendendo com as Inovações na Escola. Porto Alegre: Artes Médicas Sul, 2000.

HERNÁNDEZ, Fernando; VENTURA, Montserrat. A Organização do Currículo por Projetos de Trabalho: o conhecimento é um caleidoscópio. Porto Alegre: Artes Médicas, 1998.

KILPATRICK, William H. The Project Method: the use of the purposeful act in education process. Teachers College Record, New York, v. 19, n. 4, p. 319-335, 1918. Disponível em: <http://www.tcrecord.org/Content.asp?ContentlD=3606>. Acesso em: 04 fev. 2015.

KOFF, Adélia Maria Nehme Simão e. Uma Agenda para a Didática Hoje: atualizando possíveis prioridades. In: LIBÂNEO, José Carlos; SUANNO, Marilza Vanessa Rosa (Org.). Didática e Escola em uma Sociedade Complexa. Goiânia: Centro de Estudos e Pesquisas em Didática, 2011. P. 133-153.

LIBÂNEO, José Carlos. Produção de Saberes na Escola: suspeitas e apostas. In: CANDAU, Vera Maria et al. (Org.). Didática, Currículo e Saberes Escolares. Rio de Janeiro: DP\&A, 2000. P. 11-45.

LIBÂNEO, José Carlos. O Campo Teórico e Profissional da Didática Hoje: entre Ítaca e o canto das sereias. In: ENCONTRO NACIONAL DE DIDÁTICA E PRÁTICAS DE ENSINO, 14., 2008, Porto Alegre. Anais... Porto Alegre: PUC-RS, 2008. P. 234-252.

LOPEZ-HURTADO QUIROZ, Luis Enrique. Trece claves para Entender la Interculturalidad en la Educación Latinoamericana. In: PRATS, Enric (Coord.). Multiculturalismo y Educación para la Equidad. Barcelona: Octaedro-OEI, 2007. P. 13-44.

MARCONDES, Maria Inês; LEITE, Miriam Soares. A Pesquisa Contemporânea em Didática: contribuições para a prática pedagógica. Educação em Revista, Belo Horizonte, v. 27, p. 205-334, 2011.

OLIVEIRA, Maria Rita Neto Sales. 20 anos de ENDIPE. In: CANDAU, Vera Maria et al. Didática, Currículo e Saberes Escolares. Rio de Janeiro: DP\&A, 2000. P. 161-176.

OLIVEIRA, Roberto Cardoso de. O Trabalho do Antropólogo: olhar, ouvir e escrever. In: OLIVEIRA, Roberto Cardoso de. O Trabalho do Antropólogo. São Paulo: UNESP/Paralelo 15, 1998. P. 17-35.

PIMENTA, Selma. A Pesquisa em Didática (1996-1999). In: CANDAU, Vera Maria et al. (Org.). Didática, Currículo e Saberes Escolares. Rio de Janeiro: DP\&A, 2000. P. 78-106.

PIMENTA, Selma et al. A Construção da Didática no GT Didática-análise de seus Referenciais. Revista Brasileira de Educação, Rio de Janeiro, v. 18, n. 52, p. 143-162, jan./mar. 2013.

Educação \& Realidade, Porto Alegre, v. 40, n. 2, p. 329-348, abr./jun. 2015. 
TORRES SANTOMÉ, Jurjo. Globalização e Interdisciplinaridade: o currículo integrado. Porto Alegre: Editora Artes Médica Sul, 1998.

TUBINO, Fidel. La Interculturalidad Crítica como Proyecto Ético-político. In: ENCUENTRO CONTINENTAL DE EDUCADORES AGUSTINOS, 2005, Lima. Disponível em: <http://oala.villanova.edu/congresos/educación/lima-ponen-02.html>. Acesso em: 15 out. 2009.

WALSH, Catherine. Interculturalidad y (de)colonialidad: perspectivas críticas y políticas. In: CONGRESO DA ASSOCIATION POUR LA RECHERCHE INTERCULTURELLE, 12., 2009, Florianópolis. Florianópolis: UFSC, 2009. P. 1-23. Mimeo.

Vera Maria Ferrão Candau tem doutorado e pós-doutorado em Educação pela Universidade Complutense de Madrid. É Professora Emérita do Departamento de Educação da PUC-Rio. Coordena o Grupo de Estudos sobre Cotidiano, Educação e Culturas (GECEC), desde 1996. Pesquisadora 1A do CNPq.

E-mail:vmfc@puc-rio.br

Adélia Maria Nehme Simão e Koff tem doutorado em Educação pela Pontifícia Universidade Católica do Rio de Janeiro. Pesquisadora associada do Grupo de Estudos sobre Cotidiano, Educação e Cultura (GECEC) do Departamento de Educação da PUC-Rio). É coordenadora editorial da Revista Novamerica.

E-mail:nehme@centroin.com.br 